\title{
Investigating the Synergistic Interaction of Diabetes, Tobacco Smoking, Alcohol Consumption, and Hypercholesterolemia on the Risk of Pancreatic Cancer: A Case-Control Study in Italy
}

\author{
Giuseppe La Torre, ${ }^{1}$ Antonella Sferrazza, ${ }^{2}$ Maria Rosaria Gualano, ${ }^{3}$ \\ Chiara de Waure, ${ }^{2}$ Gennaro Clemente, ${ }^{4}$ Agostino Maria De Rose, ${ }^{4}$ Nicola Nicolotti, ${ }^{2}$ \\ Gennaro Nuzzo, ${ }^{4}$ Roberta Siliquini, ${ }^{3}$ Antonio Boccia, ${ }^{1}$ and Walter Ricciardi ${ }^{2}$ \\ ${ }^{1}$ Sapienza university of Rome, Piazzale Aldo Moro 5, 00185 Rome, Italy \\ ${ }^{2}$ Institute of Public Health, Catholic University of the Sacred Heart, Rome, Italy \\ ${ }^{3}$ Department of Public Health Sciences, University of Turin, Turin, Italy \\ ${ }^{4}$ Department of Surgery, Hepatobiliary Unit, Catholic University of the Sacred Heart, Italy
}

Correspondence should be addressed to Giuseppe La Torre; giuseppe.latorre@uniromal.it

Received 18 February 2014; Accepted 23 April 2014; Published 29 April 2014

Academic Editor: Moritz Wente

Copyright (C) 2014 Giuseppe La Torre et al. This is an open access article distributed under the Creative Commons Attribution License, which permits unrestricted use, distribution, and reproduction in any medium, provided the original work is properly cited.

\begin{abstract}
The aims of the present research are to investigate the possible predictors of pancreatic cancer, in particular smoking status, alcohol consumption, hypercholesterolemia, and diabetes mellitus, in patients with histologically confirmed pancreatic carcinoma and to examine the synergism between risk factors. A case-control study (80 patients and 392 controls) was conducted at the Teaching Hospital "Agostino Gemelli" in Rome. A conditional logistic regression was used for the statistical analysis and results were presented as odds ratio (OR) and $95 \%$ confidence intervals $(95 \% \mathrm{CI})$. We also investigated the possible interactions between risk factors and calculated the synergism index (SI). The multivariate analysis revealed that hypercholesterolemia and alcohol consumption resulted in important risk factors for pancreatic cancer even after the adjustment for all variables (OR: 5.05, 95\% CI: 2.94-8.66; OR: 2.25, 95\% CI: 1.30-3.89, resp.). Interestingly, important synergistic interactions between risk factors were found, especially between ever smoking status and alcohol consumptions $(\mathrm{SI}=17.61)$ as well as alcohol consumption and diabetes $(\mathrm{SI}=$ 17.77). In conclusion, the study confirms that hypercholesterolemia and alcohol consumption represent significant and independent risk factors for pancreatic cancer. Moreover, there is evidence of synergistic interaction between diabetes and lifestyle factors (drinking alcohol and eating fatty foods).
\end{abstract}

\section{Background}

Pancreatic cancer is a relative uncommon disease and will remain a challenging problem in the 21st century [1]. The last international cancer statistics report that it is at the 13th position for annual incidence and the 10th for mortality rate worldwide [2]. In particular, in the developed countries, it represents the ninth most common cancer in both sexes and the fifth and fourth for mortality rates, in males and females, respectively [3]. In addition, it is one of the most aggressive cancers, with an overall 5-year survival rate of less than 5\% [4].

To date, aetiology of pancreatic cancer is largely unknown and no screening tests for early detection are available. The identification of risk factors could provide a tool for primary prevention leading to reduce the burden of disease. Among risk factors of this cancer, there is evidence that tobacco smoking, alcohol abuse, hypercholesterolemia, and diabetes play an important role. However, there is no evidence on the synergistic effect of these risk factors combined. 
Tobacco smoking is a major risk factor of pancreatic cancer [4]. Epidemiological studies underline a strong association between pancreatic tumor and smoking status [5].

Carcinogens derived from tobacco smoke probably reach the pancreas via the bloodstream after being absorbed from the lungs or from the upper aerodigestive tract. In addition, there is a possibility that ingested tobacco products reach the pancreas directly after reflux into the pancreatic ductal system from the duodenum [6]. In particular, nicotine, the major component in cigarette smoke, could be implicated in pancreatic danger, causing alteration in the signal transduction pathways and in the expression of protooncogene in pancreatic cells [7].

A recent meta-analysis [8] has estimated a risk of pancreatic cancer (RR) of 1.74 (95\% CI: 1.61-1.87) for current smokers and of 1.20 (95\% CI: 1.11-1.29) for former ones.

Alcohol abuse is one of the most common causes of acute pancreatitis that is the predominant cause of chronic pancreatitis. The latter is a major risk factor for the development of pancreatic cancer [9]. To consider alcohol consumption as a risk factor for pancreatic cancer is still controversial: some authors found a positive association [10-14] while others found an inverse correlation $[15,16]$. Moreover it is important to consider that the smoking status could be a confounder for this association [17]. Recent data from pooled analyses in consortia involving multiple case-control and cohort studies suggest that heavy (but not moderate or light) alcohol consumption also may increase pancreatic cancer risk [18].

Another important risk factor for developing pancreatic cancer is metabolic syndrome: a recent meta-analysis has concluded that metabolic syndrome and its components, such as hypercholesterolemia, are associated with higher risk of this type of malignancy [19].

In several papers, the association with diabetes mellitus has been studied but further studies are needed to clarify if diabetes mellitus represents a risk factor or a consequence of pancreatic tumour [20]. In a case-control study, people with diabetes for more than 5 years before a diagnosis of pancreatic tumour have $\mathrm{RR}=2.07$ (95\% CI: $1.02-4.20)$. The risk of pancreatic cancer was 6.21 (95\% CI: 1.61-23.96) for patients treated with insulin and 1.21 (95\% CI: 0.50-2.92) for those treated with oral hypoglycemic drugs [21]. Given this context, the aims of the present research were

(i) to investigate the possible predictors of pancreatic cancer, in particular smoking status, alcohol consumption, hypercholesterolemia, and diabetes mellitus, in patients with histologically confirmed pancreatic carcinoma;

(ii) to examine the synergism between risk factors.

\section{Methods}

2.1. Patients and Setting. A case-control study was conducted at the Teaching Hospital "Agostino Gemelli" in Rome. The inclusion criteria for cases were being a patient with histologically confirmed pancreatic carcinoma, resected in the Department of Surgery-Hepatobiliary Unit, during the period 2005-2008. Sample size calculations were based on the following assumptions:

(i) prevalence of cigarette smoking among general population in 2003: 27.6\% (ISTAT 2006);

(ii) association between smoking and pancreatic cancer: $\mathrm{RR}=2.10$ (Does quality of observational studies affect the results of a meta-analysis?): the case of cigarette smoking and pancreatic cancer [22];

(iii) rate between cases and controls $=1: 5$, in order to get sufficient power.

Using these parameters, we calculated with Epi Info the need to recruit 80 cases and 400 controls. According to the methodology used in previous studies [23, 24], the controls, with no diagnosis of cancer, were recruited at the same hospital selecting randomly outpatients without a diagnosis of cancer. Those controls were matched for age $( \pm 5$ years) and gender with cases, in a ratio 5 to 1 . The study participants were selected and directly interviewed by welltrained interviewers. All the participants gave their informed consent to participate and, according to the Italian law, a notification of the study was transmitted to the local ethical committee.

2.2. Data Collection. Information on the following variables was collected through patient history questions during the first clinical examination, in particular

(i) type-II diabetes diagnosed before the interview;

(ii) smoking habits (current smoking, former smoking, or never smoking);

(iii) alcohol consumption (drink of at least a glass of wine, beer, or hard liquor per day).

(iv) hypercholesterolemia;

(v) age and gender.

The presence in the patient history of diabetes and hypercholesteremia was subsequently confirmed by laboratory parameters and/or medication.

2.3. Statistical Analysis. Descriptive statistics was performed using frequencies, percentages, frequency tables for qualitative variables, and mean \pm standard deviation $(\mathrm{SD})$ for quantitative variables.

For the univariate analysis Mann-Whitney and chi-square tests were used. Differences in frequencies between the cases and controls were evaluated by chi-square test and Fisher exact probability test.

In order to investigate the risk factors for pancreatic cancer, a conditional logistic regression model was used, following a multiplicative model, and results were presented as odds ratio (OR) and 95\% confidence intervals (95\% CI). Variables entering the model were selected according to the Hosmer and Lemeshow procedures [25].

Concerning the smoking habits, cases and controls were classified as ever smokers (current or former smokers) and no 
TABLE 1: Characteristics of cases and controls.

\begin{tabular}{lccc}
\hline $\begin{array}{l}\text { Variables } \\
(N=320)\end{array}$ & $\begin{array}{c}\text { Cases } \\
(\%)\end{array}$ & $\begin{array}{c}\text { Controls } \\
(\%)\end{array}$ & $P^{\wedge}$ \\
\hline Gender & & & \\
$\quad$ Males & $45(56.3)$ & $204(52)$ & 0.492 \\
$\quad$ Females & $35(43.8)$ & $188(48)$ & \\
Age, mean (SD) & $63.59(11.05)$ & $64.92(10.95)$ & $0.319^{*}$ \\
Diabetes mellitus & & & \\
$\quad$ Yes & $19(23.8)$ & $54(13.8)$ & $\mathbf{0 . 0 2 5}$ \\
$\quad$ No & $61(76.3)$ & $338(86.2)$ & \\
Ever smoking & & & \\
$\quad$ Yes & $34(42.5)$ & $107(27.3)$ & $\mathbf{0 . 0 0 7}$ \\
$\quad$ No & $46(57.5)$ & $285(72.7)$ & \\
Alcohol consumption & & & \\
$\quad$ Yes & $41(51.3)$ & $103(26.3)$ & $<\mathbf{0 . 0 0 1}$ \\
$\quad$ No & $39(48.7)$ & $289(73.7)$ & \\
Hypercholesterolemia & & & \\
$\quad$ Yes & $40(50)$ & $56(14.3)$ & $<\mathbf{0 . 0 0 1}$ \\
$\quad$ No & $40(50)$ & $336(85.7)$ & \\
\hline
\end{tabular}

${ }^{\wedge}$ Chi-square test.

* Mann-Whitney test.

smokers, while the alcohol consumption was classified as no drink versus at least one drink/day.

The synergism index was calculated as follows: $S=$ $[$ OR11 -1$] /([\mathrm{OR} 01+$ OR10] -2$)$, where OR11 is equal to OR of the joint effect of two risk factors and OR10 and OR01 are equal to $\mathrm{OR}$ of each risk factor in the absence of the other. A value of $S$ equal to unity was interpreted as indicative of additivity, whereas a value greater than unity was indicative of superadditivity and synergism [26, 27].

Finally, the population attributable risk percentage (PAR\%) for each statistically significant risk factor was calculated using the adjusted OR of that factor and its prevalence in the control group $(\mathrm{Pe})$ [28].

Statistical significance level was set at $P=0.05$. Statistical analyses were performed using the statistical software Stata release 9.0 .

\section{Results}

Eighty cases and 392 controls were analysed. Among matched patients $56.3 \%$ were males. The mean ages of cases and controls were, respectively, 63.6 and 64.8 years. As shown in Table 1, statistically significant differences for having a pancreatic cancer emerged for diabetes mellitus: in fact it appeared that diabetic patients had a higher probability to be affected by pancreatic cancer $(P=0.025)$.

For the variables ever smoking, alcohol consumption, and hypercholesterolemia, there were statistically significant differences $(P=0.007, P<0.001$, and $P<0.001$, resp.): ever smokers, drinkers, and patients with hypercholesterolemia had a higher likelihood to develop a pancreatic cancer.

As shown in the Table 2, hypercholesterolemia and alcohol consumption resulted in important risk factors for
TABLE 2: Adjusted odds ratios of the selected variables.

\begin{tabular}{|c|c|c|}
\hline Variables $(N=320)$ & $\begin{array}{c}\text { Crude OR } \\
(95 \% \text { CI })\end{array}$ & $\begin{array}{c}\text { Adjusted OR } \\
(95 \% \mathrm{CI})^{*}\end{array}$ \\
\hline \multicolumn{3}{|l|}{ Gender } \\
\hline Males (reference) & 1 & 1 \\
\hline Females & $1.04(0.78-1.40)$ & $1.16(0.81-1.65)$ \\
\hline Age & $0.99(0.97-1.01)$ & $0.99(0.96-1.01)$ \\
\hline \multicolumn{3}{|l|}{ Diabetes } \\
\hline No & 1 & 1 \\
\hline Yes & $1.95(1.08-3.52)$ & $1.64(0.84-3.21)$ \\
\hline \multicolumn{3}{|l|}{ Hypercholesterolemia } \\
\hline No & 1 & 1 \\
\hline Yes & $\begin{array}{c}6.00 \\
(3.56-10.11)\end{array}$ & $\begin{array}{c}5.05 \\
(2.94-8.66)\end{array}$ \\
\hline \multicolumn{3}{|l|}{ Ever smoking } \\
\hline No & 1 & 1 \\
\hline Yes & $1.97(1-20-3.23)$ & $1.28(0.72-2.29)$ \\
\hline \multicolumn{3}{|l|}{ Alcohol consumption } \\
\hline No & 1 & 1 \\
\hline Yes & $2.95(1.80-4.83)$ & $2.25(1.30-3.89)$ \\
\hline
\end{tabular}

pancreatic cancer even after the adjustment for all variables (OR: 5.05, 95\% CI: 2.94-8.66; OR: 2.25, 95\% CI: 1.30-3.89, resp.).

Using the prevalence of pancreatic risk factors in the controls and the estimated adjusted ORs of them, we estimated that the PAR\% values explained by the diabetes mellitus, ever cigarette smoking, alcohol consumption, and hypercholesterolemia in our study population were $10.9,8.6 \%, 13.9 \%$, and $29.8 \%$, respectively.

In Table 3 the joint effect of ever cigarette smoking, alcohol consumption, diabetes mellitus, and hypercholesterolemia on pancreatic cancer risk was shown. It is clear that there was an indication for the additivity and synergism between risk factors, especially between ever smoking status and alcohol consumptions, as well as alcohol consumption and diabetes.

\section{Discussion}

Our study investigated risk factors of a relative uncommon cancer and went deep in the synergic association between well known risk factors of pancreatic cancer. Results of our multivariate analysis confirmed that alcohol consumption and hypercholesterolemia are significant risk factors for pancreatic cancer.

Regarding the study of the interactions between variables, it clearly showed that there was an indication for the additivity and synergism between risk factors, especially between ever smoking status and alcohol consumptions, as well as alcohol consumption and diabetes.

Tobacco smoking is universally reported as an environmental risk factor for pancreatic cancer and accounts for 
TABLE 3: Synergistic interaction between ever smoking and diabetes, alcohol consumption and diabetes, and alcohol consumption and ever smoking.

\begin{tabular}{|c|c|c|c|}
\hline \multicolumn{2}{|c|}{ Variables $(N=320)$} & $\operatorname{AOR}(95 \% \mathrm{CI})^{*}$ & Synergistic interaction \\
\hline Ever smoking & Diabetes & & \multirow{5}{*}{4.93} \\
\hline No & No (reference) & 1 & \\
\hline Yes & No & $1.42(0.84-2.41)$ & \\
\hline No & Yes & $1.19(0.57-2.48)$ & \\
\hline Yes & Yes & $4.01(1.63-9.88)$ & \\
\hline Ever smoking & Hypercolesterol & & \multirow{5}{*}{1.32} \\
\hline No & No (reference) & 1 & \\
\hline Yes & No & $0.86(0.47-1.58)$ & \\
\hline No & Yes & $4.00(2.16-7.41)$ & \\
\hline Yes & Yes & $4.78(2.47-9.24)$ & \\
\hline Alcohol consumption & Ever smoking & & \multirow{5}{*}{17.61} \\
\hline No & No (reference) & 1 & \\
\hline Yes & No & $1.48(0.78-2.78)$ & \\
\hline No & Yes & $0.65(0.30-1.43)$ & \\
\hline Yes & Yes & $3.29(1.89-5.73)$ & \\
\hline Alcohol consumption & Diabetes & & \\
\hline No & No (reference) & 1 & \multirow{4}{*}{17.77} \\
\hline Yes & No & $1.48(0.78-2.78)$ & \\
\hline No & Yes & $0.65(0.30-1.43)$ & \\
\hline Yes & Yes & $3.31(1.50-7.32)$ & \\
\hline Alcohol consumption & Hypercolesterolemia & & \multirow{5}{*}{1.30} \\
\hline No & No (reference) & 1 & \\
\hline Yes & No & $1.41(0.81-2.50)$ & \\
\hline No & Yes & $3.75(2.01-6.98)$ & \\
\hline Yes & Yes & $5.11(2.66-9.82)$ & \\
\hline Diabetes & Hypercolesterolemia & & \multirow{5}{*}{3.68} \\
\hline No & No (reference) & 1 & \\
\hline Yes & No & $0.61(0.25-1.48)$ & \\
\hline No & Yes & $3.65(2.10-6.35)$ & \\
\hline Yes & Yes & $9.31(3.72-23.33)$ & \\
\hline
\end{tabular}

${ }^{*}$ AOR: odds ratio adjusted for work activity, diabetes mellitus, ever smoking, and alcohol consumption.

approximately $25 \%$ of all pancreatic cancers [29]. Smoking always should be measured and adjusted for in etiologic epidemiologic studies of pancreatic cancer and encouraging nonsmoking should reduce the incidence of the disease [29, 30].

Furthermore, the significant association between diabetes and pancreatic malignancy was reported in several studies $[21,31-35]$ and in a meta-analysis also [36]. In our study, risk for pancreatic cancer was demonstrated almost twofold higher among patients affected by diabetes and around threefold among smokers, but the crude odds ratios are not confirmed at the multivariate analysis (Table 2), suggesting the presence of factors confounding the analysis.

In our study alcohol consumption appears to be associated with pancreatic cancer, in line with results of previous studies [37-39].

Interestingly, the higher risk of pancreatic cancer seems to be related to hypercholesterolemia. This finding is in accordance with a case-control study and a meta-analysis investigating the association of metabolic syndrome and pancreatic cancer [19].

Additionally, we estimated that if the diabetes mellitus, cigarette smoking, alcohol consumption, and hypercholesterolemia are associated with pancreatic cancer independently of each other, each factor contributed to $10.9,8.6 \%$, $13.9 \%$, and $29.8 \%$ of the pancreatic cancer cases in this study, respectively. In a study conducted by Hassan et al. [28] similar results were found concerning diabetes mellitus and ever smoking. About alcohol consumption, results are not comparable because the authors considered only the heavy alcohol consumption. Talamini et al. in 2010 found that tobacco smoking and alcohol drinking are two independent risk factors for pancreatic cancer which may be responsible for around 33\% of these cancers [40].

Moreover, a clear indication for the additivity between these risk factors, especially between ever smoking status and alcohol consumptions as well as alcohol consumption and diabetes, was shown in our research. 
Few studies have analyzed the potential interaction between smoking and other risk factors, focusing particularly on genetic ones $[41,42]$ and concluding that further investigations are needed in this direction. To date, no studies investigated the interaction between diabetes mellitus, hypercholesterolemia, and alcohol consumption.

In interpreting our results the main limitations of our study should be acknowledged. Firstly, given the study design, a risk of underreporting and recall bias has to be addressed: these factors can give an underestimation of the prevalence of drinkers and smokers. Secondly, we have to consider that information about family history of pancreatic cancer is lacking. A further limitation consists in the lacking of information about use of aspirin $[43,44]$, physical activity [45], and reproductive factors [46, 47], as well as date of onset and type of medication for diabetes mellitus. Moreover, using the synergistic effect, there is no practical solution to sample sizing considering at least two risk factors simultaneously. However, we really believe that the case-control study was sufficiently powered looking at the results of Table 2 , and no selection bias should be due to this aspect.

Finally, the use of a hospital-based case-control study design may overestimate the prevalence of exposure for some risk factors, such as smoking, diabetes mellitus, and alcohol consumption. However, if this was the case, even if misclassification of exposure occurred, our results could give OR towards the null, and the synergistic hypothesis would be confirmed.

On the contrary, a strength of this study was the statistical analysis: we performed a conditional logistic regression model in order to analyze matched data. Moreover, this study adds knowledge on synergism between risk factors for pancreatic cancer that is a little explored topic.

In conclusion, the present study confirms that, after controlling for possible confounding factors, hypercholesterolemia and alcohol consumption represent significant and independent risk factors for pancreatic cancer. Moreover, there is evidence of synergistic interaction between diabetes and lifestyle factors (drinking alcohol and eating fatty foods).

We believe that identifying individuals at the highest risk for pancreatic cancer could be a great opportunity in order to develop prevention programmes and early detection of pancreatic cancer.

\section{Conflict of Interests}

The authors declare that they have no conflict of interests.

\section{References}

[1] D. Li, K. Xie, R. Wolff, and J. L. Abbruzzese, "Pancreatic cancer," The Lancet, vol. 363, no. 9414, pp. 1049-1057, 2004.

[2] J. Ferlay, H.-R. Shin, F. Bray, D. Forman, C. Mathers, and D. M. Parkin, "Estimates of worldwide burden of cancer in 2008: GLOBOCAN 2008," International Journal of Cancer, vol. 127, no. 12, pp. 2893-2917, 2010.

[3] A. Jemal, F. Bray, M. M. Center, J. Ferlay, E. Ward, and D. Forman, "Global cancer statistics," CA Cancer Journal for Clinicians, vol. 61, no. 2, pp. 69-90, 2011.
[4] S. J. Pandol, M. V. Apte, J. S. Wilson, A. S. Gukovskaya, and M. Edderkaoui, "The burning question: why is smoking a risk factor for pancreatic cancer?” Pancreatology, vol. 12, no. 4, pp. 344-349, 2012.

[5] K. Matsuo, H. Ito, K. Wakai et al., "Cigarette smoking and pancreas cancer risk: an evaluation based on a systematic review of epidemiologic evidence in the Japanese population," Japanese Journal of Clinical Oncology, vol. 41, no. 11, Article ID hyr141, pp. 1292-1302, 2011.

[6] A. B. Lowenfels and P. Maisonneuve, "Epidemiology and prevention of pancreatic cancer," Japanese Journal of Clinical Oncology, vol. 34, no. 5, pp. 238-244, 2004.

[7] P. Chowdhury, S. MacLeod, K. B. Udupa, and P. L. Rayford, "Pathophysiological effects of nicotine on the pancreas: an update," Experimental Biology and Medicine, vol. 227, no. 7, pp. 445-454, 2002.

[8] S. Iodice, S. Gandini, P. Maisonneuve, and A. B. Lowenfels, "Tobacco and the risk of pancreatic cancer: a review and metaanalysis," Langenbeck's Archives of Surgery, vol. 393, no. 4, pp. 535-545, 2008.

[9] M. Apte, R. Pirola, and J. Wilson, "New insights into alcoholic pancreatitis and pancreatic cancer," Journal of gastroenterology and hepatology, vol. 24, pp. S51-S56, 2009.

[10] W. Zheng, J. K. McLaughlin, G. Grinndley et al., "A cohort study of smoking, alcohol consumption, and dietary factors for pancreatic cancer (United States)," Cancer Causes and Control, vol. 4, no. 5, pp. 477-482, 1993.

[11] G. W. Olsen, J. S. Mandel, R. W. Gibson, L. W. Wattenberg, and L. M. Schuman, "A case-control study of pancreatic cancer and cigarettes, alcohol, coffee and diet," American Journal of Public Health, vol. 79, no. 8, pp. 1016-1019, 1989.

[12] J. Cuzick and A. G. Babiker, "Pancreatic cancer, alcohol, diabetes mellitus and gall-bladder disease," International Journal of Cancer, vol. 43, no. 3, pp. 415-421, 1989.

[13] E. L. Wynder, G. S. Dieck, and N. E. L. Hall, "Case-control study of decaffeinated coffee consumption and pancreatic cancer," Cancer Research, vol. 46, no. 10, pp. 5360-5363, 1986.

[14] I. Heuch, G. Kvale, B. K. Jacobsen, and E. Bjelke, "Use of alcohol, tobacco and coffee, and risk of pancreatic cancer," British Journal of Cancer, vol. 48, no. 5, pp. 637-643, 1983.

[15] P. A. Baghurst, A. J. McMichael, A. H. Slavotinek, K. I. Baghurst, P. Boyle, and A. M. Walker, "A case-control study of diet and cancer of the pancreas," American Journal of Epidemiology, vol. 134, no. 2, pp. 167-179, 1991.

[16] P. Ghadirian, A. Simard, and J. Baillargeon, "Tobacco, alcohol, and coffee and cancer of the pancreas: a population-based, casecontrol study in Quebec, Canada," Cancer, vol. 67, no. 10, pp. 2664-2670, 1991.

[17] W. Ye, J. Lagergren, E. Weiderpass, O. Nyrén, H.-O. Adami, and A. Ekbom, "Alcohol abuse and the risk of pancreatic cancer," Gut, vol. 51, no. 2, pp. 236-239, 2002.

[18] E. J. Duell, "Epidemiology and potential mechanisms of tobacco smoking and heavy alcohol consumption in pancreatic cancer," Molecular Carcinogenesis, vol. 51, no. 1, pp. 40-52, 2012.

[19] V. Rosato, A. Tavani, C. Bosetti et al., "Metabolic syndrome and pancreatic cancer risk: a case-control study in Italy and metaanalysis," Metabolism: Clinical and Experimental, vol. 60, no. 10, pp. 1372-1378, 2011.

[20] S. T. Chari, C. L. Leibson, K. G. Rabe et al., "Pancreatic cancer-associated diabetes mellitus: prevalence and temporal association with diagnosis of cancer," Gastroenterology, vol. 134, no. 1, pp. 95-101, 2008. 
[21] L. Bonelli, H. Aste, P. Bovo et al., "Exocrine pancreatic cancer, cigarette smoking, and diabetes mellitus: a case-control study in Northern Italy," Pancreas, vol. 27, no. 2, pp. 143-149, 2003.

[22] G. La Torre, C. De Waure, M. L. Specchia et al., "Does quality of observational studies affect the results of a meta-analysis?: the case of cigarette smoking and pancreatic cancer," Pancreas, vol. 38, no. 3, pp. 241-247, 2009.

[23] M. Soler, L. Chatenoud, C. La Vecchia, S. Franceschi, and E. Negri, "Diet, alcohol, coffee and pancreatic cancer: final results from an Italian study," European Journal of Cancer Prevention, vol. 7, no. 6, pp. 455-460, 1998.

[24] R. J. Menezes, K. R. Huber, M. C. Mahoney, and K. B. Moysich, "Regular use of aspirin and pancreatic cancer risk," BMC Public Health, vol. 2, no. 1, p. 18, 2002.

[25] D. W. Hosmer and S. Lemeshow, Applied Logistic Regression, John Wiley \& Sons, New York, NY, USA, 1989.

[26] K. J. Rothman, S. Greenland, and T. Lash, Modern Epidemiology, Lippincott Williams, 3rd edition, 2008.

[27] K. J. Rothman, "The estimation of synergy or antagonism," American Journal of Epidemiology, vol. 103, no. 5, pp. 506-511, 1976.

[28] M. M. Hassan, M. L. Bondy, R. A. Wolff et al., "Risk factors for pancreatic cancer: case-control study," American Journal of Gastroenterology, vol. 102, no. 12, pp. 2696-2707, 2007.

[29] A. B. Lowenfels and P. Maisonneuve, "Epidemiology and risk factors for pancreatic cancer," Best Practice and Research: Clinical Gastroenterology, vol. 20, no. 2, pp. 197-209, 2006.

[30] P. J. Villeneuve, K. C. Johnson, Y. Mao et al., "Environmental tobacco smoke and the risk of pancreatic cancer: findings from a Canadian population-based case-control study," Canadian Journal of Public Health, vol. 95, no. 1, pp. 32-37, 2004.

[31] L. Wideroff, G. Gridley, L. Mellemkjaer et al., "Cancer incidence in a population-based cohort of patients hospitalized with diabetes mellitus in denmark," Journal of the National Cancer Institute, vol. 89, no. 18, pp. 1360-1365, 1997.

[32] W.-H. Chow, G. Gridley, O. Nyren et al., "Risk of pancreatic cancer following diabetes mellitus: a nationwide cohort study in Sweden," Journal of the National Cancer Institute, vol. 87, no. 12, pp. 930-931, 1995.

[33] E. E. Calle, T. K. Murphy, C. Rodriguez, M. J. Thun, and C. W. Heath Jr., "Diabetes mellitus and pancreatic cancer mortality in a prospective cohort of United States adults," Cancer Causes and Control, vol. 9, no. 4, pp. 403-410, 1998.

[34] G. D. Smith, M. Egger, M. J. Shipley, and M. G. Marmot, "Postchallenge glucose concentration, impaired glucose tolerance, diabetes, and cancer mortality in men," American Journal of Epidemiology, vol. 136, no. 9, pp. 1110-1114, 1992.

[35] D. T. Silverman, "Risk factors for pancreatic cancer: a casecontrol study based on direct interviews," Teratog Carcinog Mutagen, vol. 21, no. 1, pp. 7-25, 2001.

[36] R. Huxley, A. Ansary-Moghaddam, A. Berrington De González, F. Barzi, and M. Woodward, "Type-II diabetes and pancreatic cancer: a meta-analysis of 36 studies," British Journal of Cancer, vol. 92, no. 11, pp. 2076-2083, 2005.

[37] M. M. Hassan, M. L. Bondy, R. A. Wolff et al., "Risk factors for pancreatic cancer: case-control study," American Journal of Gastroenterology, vol. 102, no. 12, pp. 2696-2707, 2007.

[38] T. J. Partanen, H. U. Vainio, I. A. Ojajärvi, and T. P. Kauppinen, "Pancreas cancer, tobacco smoking and consumption of alcoholic beverages: a case-control study," Cancer Letters, vol. 116, no. 1, pp. 27-32, 1997.
[39] W. Zheng, J. K. McLaughlin, G. Grinndley et al., "A cohort study of smoking, alcohol consumption, and dietary factors for pancreatic cancer (United States)," Cancer Causes and Control, vol. 4, no. 5, pp. 477-482, 1993.

[40] R. Talamini, J. Polesel, S. Gallus et al., "Tobacco smoking, alcohol consumption and pancreatic cancer risk: a case-control study in Italy," European Journal of Cancer, vol. 46, no. 2, pp. 370-376, 2010.

[41] L. W. Xing and J. Wang, "Smoking-gene interaction and disease development: relevance to pancreatic cancer and atherosclerosis," World Journal of Surgery, vol. 29, no. 3, pp. 344-353, 2005.

[42] N. Malats, "Gene-environment interactions in pancreatic cancer," Pancreatology, vol. 1, no. 5, pp. 472-476, 2001.

[43] R. J. Menezes, K. R. Huber, M. C. Mahoney, and K. B. Moysich, "Regular use of aspirin and pancreatic cancer risk," BMC Public Health, vol. 2, no. 1, p. 18, 2002.

[44] E. S. Schernhammer, J.-H. Kang, A. T. Chan et al., "A prospective study of aspirin use and the risk of pancreatic cancer in women," Journal of the National Cancer Institute, vol. 96, no. 1, pp. 22-28, 2004.

[45] P. J. Sinner, K. H. Schmitz, K. E. Anderson, and A. R. Folsom, "Lack of association of physical activity and obesity with incident pancreatic cancer in elderly women," Cancer Epidemiology Biomarkers and Prevention, vol. 14, no. 6, pp. 1571-1573, 2005.

[46] S. M. Wörmann and H. Algül, "Risk factors and therapeutic targets in pancreatic cancer," Frontiers in Oncology, vol. 3, p. 282, 2013.

[47] L. R. Teras, A. V. Patel, C. Rodriguez, M. J. Thun, and E. E. Calle, "Parity, other reproductive factors, and risk of pancreatic cancer mortality in a large cohort of U.S. Women (United States)," Cancer Causes and Control, vol. 16, no. 9, pp. 1035-1040, 2005. 


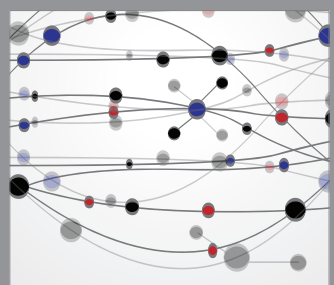

The Scientific World Journal
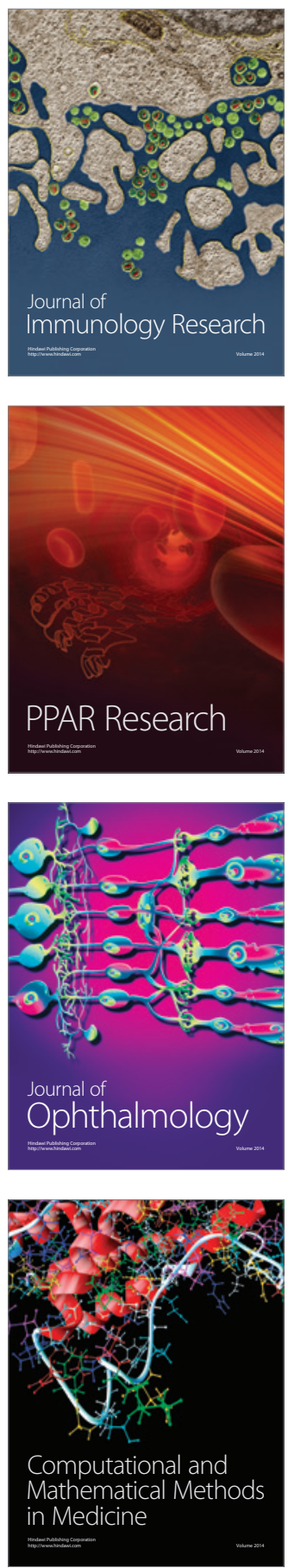

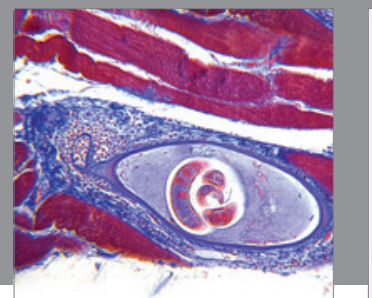

Gastroenterology

Research and Practice
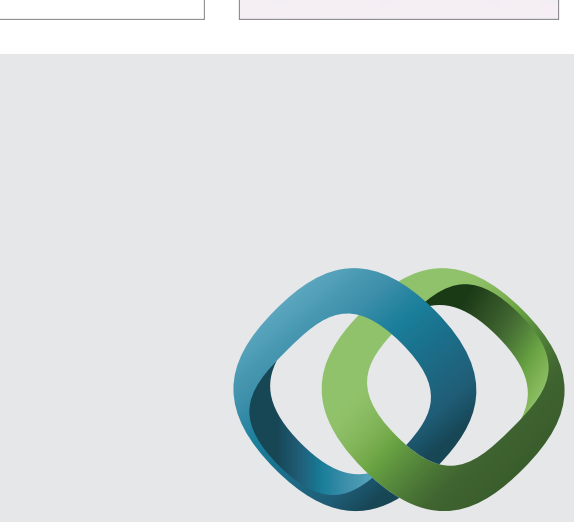

\section{Hindawi}

Submit your manuscripts at

http://www.hindawi.com
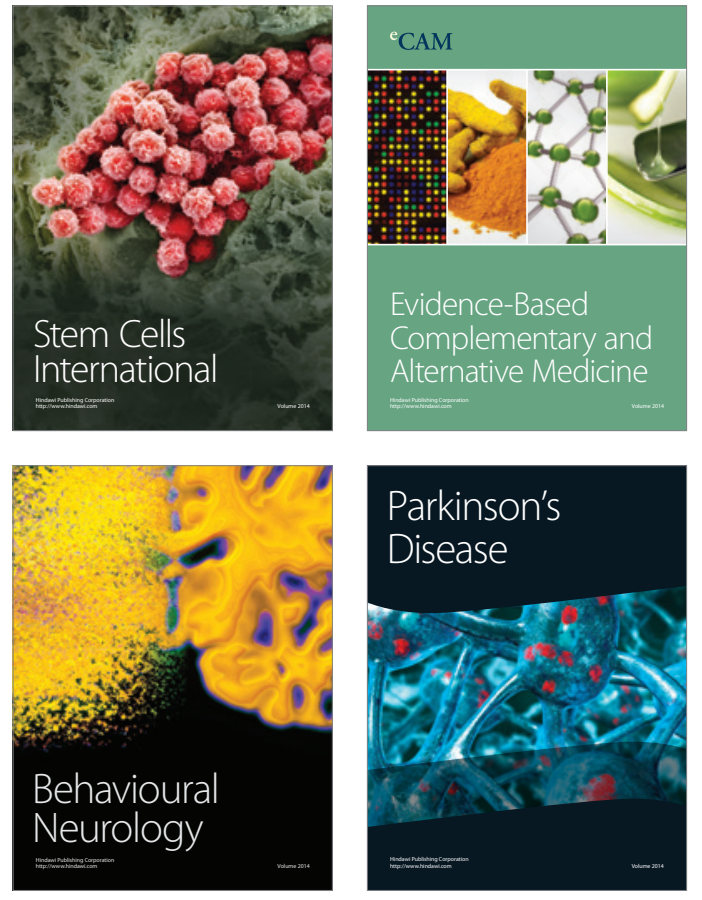
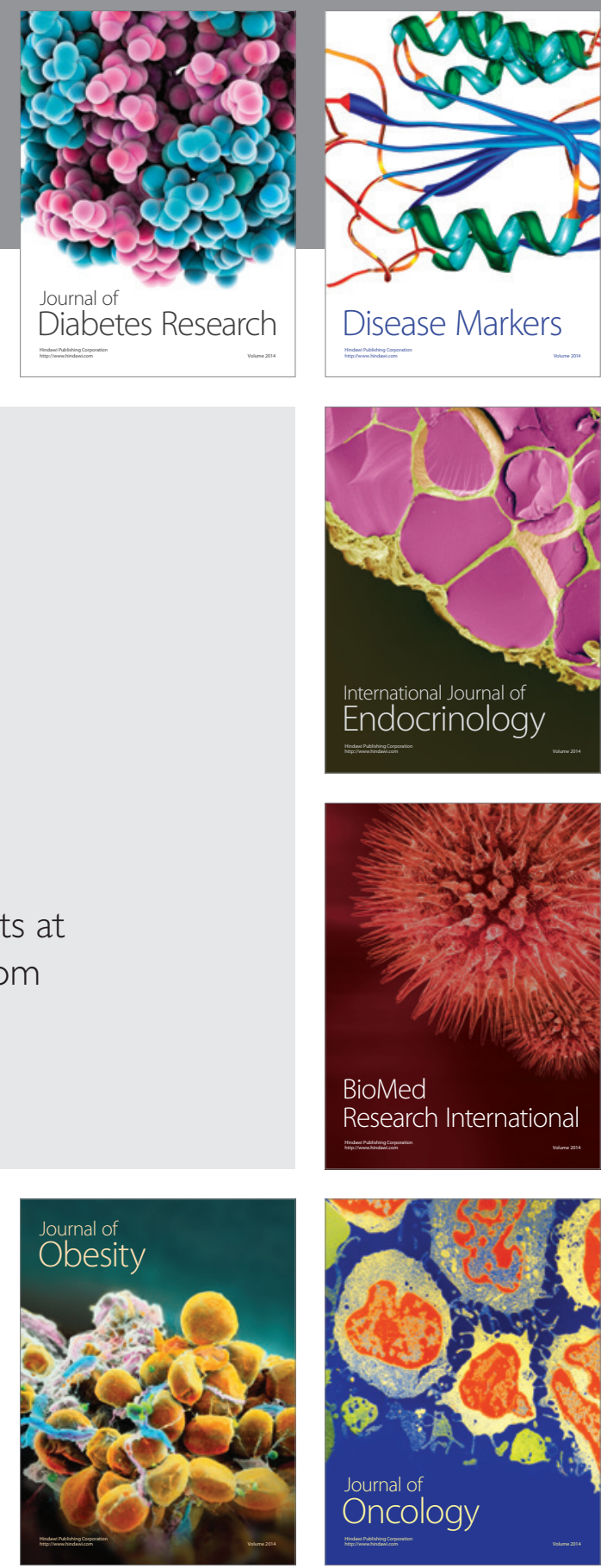

Disease Markers
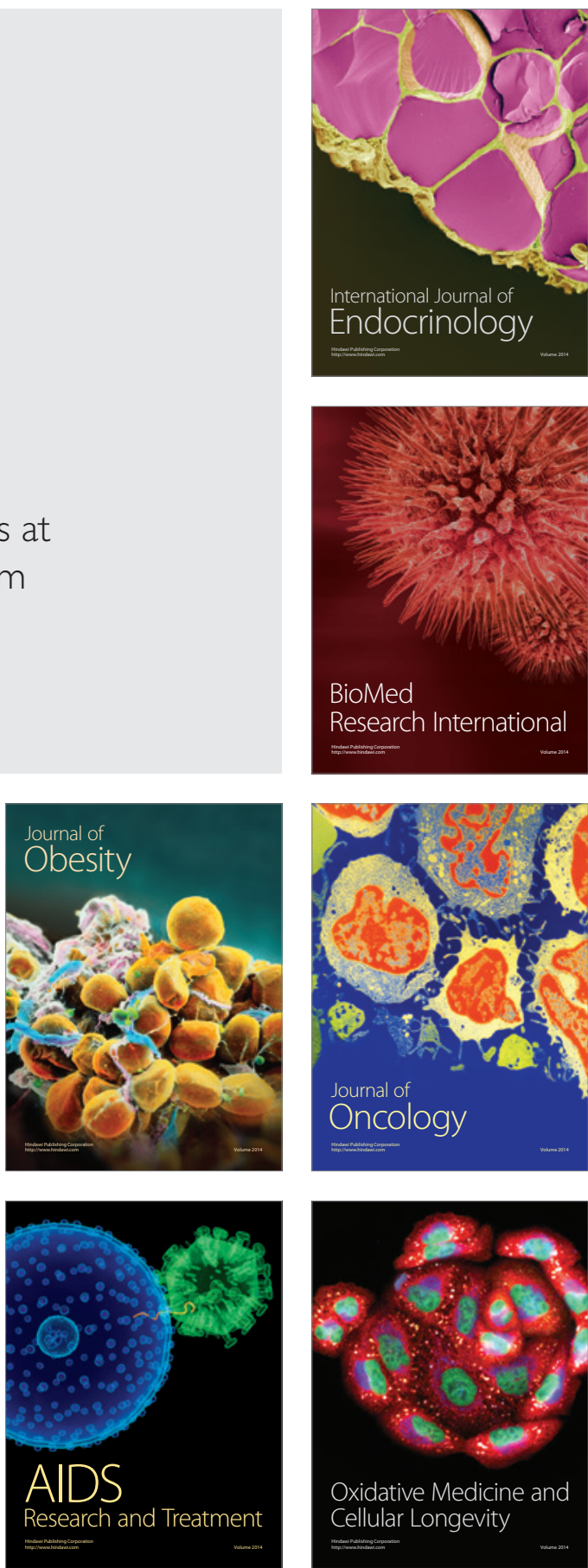